\title{
LIDAR INVESTIGATIONS OF THERMAL REGIME AND AEROSOL STRATIFICATION OF THE STRATOSPHERE OVER TOMSK
}

\author{
Gennady Matvienko, Valeriy Marichev, Dmitry Bochkovsky \\ V.E. Zuev Institute of Atmospheric Optics, Siberian Branch of the Russian Academy of Sciences, \\ Academician Zuev Square, Tomsk 634055,Russia, E-mail:mgg@iao.ru
}

\begin{abstract}
One of the important applications of lidar techniques is the study of thermal regime and aerosol content of the stratosphere. Such investigations in monitoring mode were started at the Institute of atmospheric optics since 1994 and are continued to date. The main attention is paid for the study of the unexpected disturbances caused by winter stratospheric warming. In this paper we present the results of the study of the vertical distribution of temperature and aerosol over Tomsk of last years.
\end{abstract}

\section{INTRODUCTION}

The period of 2015-16, which presents the results was characterized by the absence of volcanic eruptions which could affect the disturbance of the aerosol component of the stratosphere of the northern hemisphere including western Siberian region. So it was a convenient possibility to observe the peculiarities of the temporal variability of the background aerosol loading of the stratosphere over Western Siberia during quite long time interval. In this period, as in previous years [15], winter stratospheric warming's were observed. This gave the opportunity to continue the study of the peculiarities of their manifestations.

The represented data array of 161 total signals collected in some nights was used as initial data for analysis in 2015-16. The height interval was from 15 till $50-60 \mathrm{~km}$, the spatial resolution was $192 \mathrm{~m}$. Lidar signals were received in the photopulses counting mode with accumulation of $12 \times 10^{4}$ laser pulses (accumulation time was about 2 hours during a night).

\section{METHODOLOGY}

Lidar methods of the Raman and elastic aerosol and molecular scattering of light (Raman, Mie and Rayleigh scattering) were used to determine the vertical profile of aerosol characteristics and temperature in the stratosphere. The atmospheric sounding was carried out by laser radiation at a wavelength of $532 \mathrm{~nm}$, the reception of the lidar signals at wavelengths 532 and $607 \mathrm{~nm}$.

The optical characteristic $\mathrm{R}(\mathrm{H})$ - aerosol scattering ratio $(\mathrm{H}$ is the current height) was used as a parameter describing the aerosol vertical stratification. By definition, $\mathrm{R}(\mathrm{H})$ is the ratio of the sum of aerosol and molecular backscattering coefficient to the molecular backscattering coefficient. For example, fulfillment of the condition $\mathrm{R}(\mathrm{H})=1$ means the absence of aerosol at the certain height, and contrary, aerosol appears where $\mathrm{R}(\mathrm{H})>1$.

The vertical profiles of temperature $\mathrm{T}(\mathrm{H})$ were retrieved from the Rayleigh and Raman signals using the formula:

$$
\begin{aligned}
T(H)=\frac{P_{1}(H) P_{2}(H)}{N(H) H^{2}} & {\left[\frac{N\left(H_{m}\right)}{P_{1}\left(H_{m}\right) P_{2}\left(H_{m}\right)} T\left(H_{m}\right)+\right.} \\
& \left.+\frac{1}{R *} \int_{H_{m}}^{H} \frac{N(h) h^{2} g(h) d h}{P_{1}(h) P_{2}(h)}\right]
\end{aligned}
$$

Here $N(H)$ - lidar signals, $P_{l}(H)$ and $P_{2}(H)$ are the transparencies of the atmosphere from the level of arrangement of the lidar up to the height $\mathrm{H}$ at the wavelength of $532 \mathrm{~nm}$ (Rayleigh signals) and 532 and $607 \mathrm{~nm}$ (Raman signals), respectively; $R^{*}$ is the universal gas constant, $g(h)$ is the gravity acceleration, $H m$ is the maximum height, from which quite reliable for processing signals are detected (so-called calibration height, at which the temperature values $T(\mathrm{Hm})$ are set).

\section{RESULTS}

\subsection{Aerosol}

The results of measurements of the monthly mean dynamics of the aerosol vertical stratification are shown in Fig. 1 and Fig.2. 


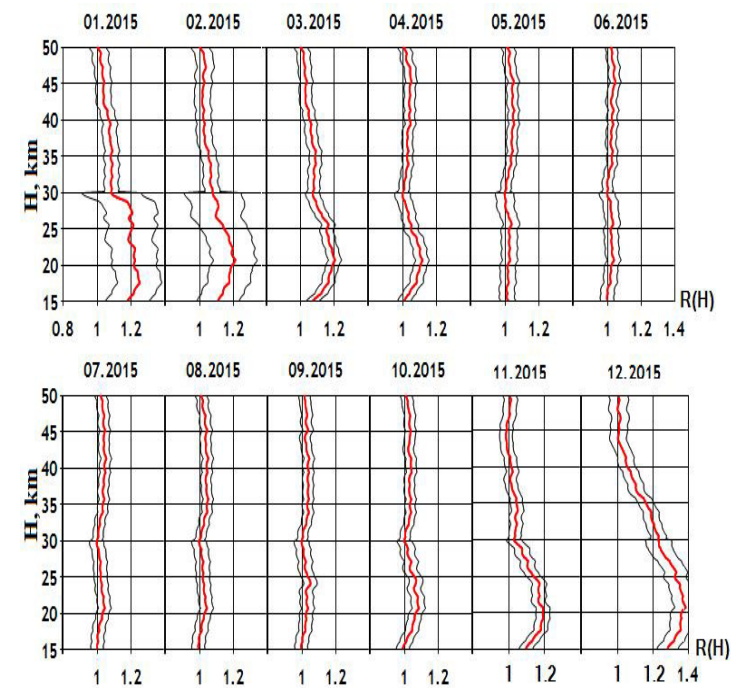

Figure 1 Monthly mean profiles of the aerosol vertical stratification in 2015. Red lines show the mean profiles, black lines show the range of standard deviation
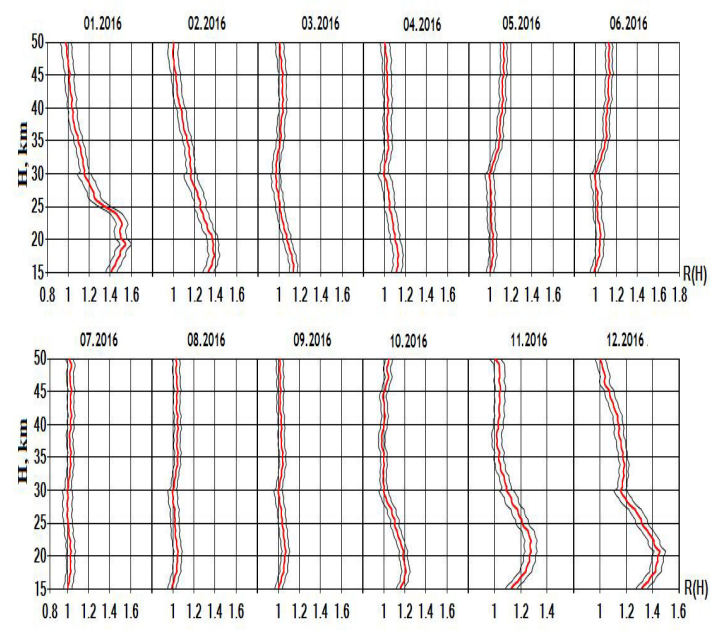

Figure 2 Monthly mean profiles of the aerosol vertical stratification in 2016

The tendency of the maximum aerosol loading of the lower stratosphere in January, decreasing in spring and practical absence of aerosol in May - September is confirmed by comparison with observations in previous years $[1,2]$. Aerosol content begins to increase in October and reaches maximum in January.

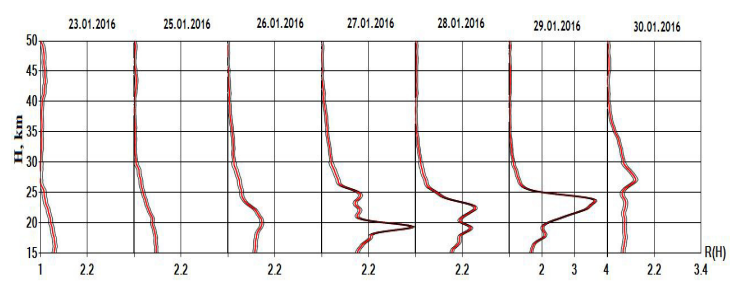

Figure 3 Dynamics of the aerosol vertical stratification in January 2016 (the appearance of polar stratospheric clouds)
The aerosol loading of the stratosphere increased significantly in the first decade of January 2016 and covered the entire stratosphere (Fig. 3). The scattering ratio achieved the maximal level $R=1.6-1.8$ at a height of $20 \mathrm{~km}$. Some decrease of the aerosol content took place in the middle of the month. Unusual aerosol stratification was detected in the third decade of the month. It was characterized by the very high aerosol content in the lower stratosphere and aerosol absence in the upper stratosphere for the most days of observation. The layered structure of the aerosol component was observed, which underwent significant vertical variations for the entire period of observations in January 23 to 30 . The scattering ratio achieved extremely high values up to $R=3.5$. The following analysis has shown that distortions of the aerosol component were caused by the appearance of polar stratospheric clouds (PSCs). Our synchronous lidar measurements of temperature discovered the abnormally low temperature values in the lower stratosphere (lower than $190 \mathrm{~K}$ ), which caused the formation of PSCs.

In March, a sharp decrease in the aerosol loading of the stratosphere was observed: there was no aerosol in the upper stratosphere, and only trace concentrations at heights from 15 to $25 \mathrm{~km}$ remained. In the following period of late spring, summer, and early fall, the aerosol component was practically absent in the entire stratospheric layer. This feature revealed, at least, for the Tomsk Region was confirmed by many-year observations.

\subsection{Temperature}

The study of thermal regime of the stratosphere in 2015 was started in the disturbed period caused by stratospheric warming (SW) $[4,5]$. The first manifestations of SW- was observed on 3 December 2014. Figures 4 and 5 show examples of the vertical profiles of temperature obtained during SW 2014-15. Lidar temperature profiles are given in comparison with the profiles of temperature measured from onboard the AURA satellite [6] and taken from the CIRA-86 model [7].

Next event of the SW began at the end of January 2015 and went on until second decade of February (see Fig. 5). Stratospheric warming in winter 2014-2015 was one of the longest SW observed over Tomsk since 1996, which prolonged almost one month. The greatest positive deviations of temperature were 
observed in the height range 40 up to $45 \mathrm{~km}$ and could reach $60 \mathrm{~K}$ at the height of $40 \mathrm{~km}$ (February 5, 2015).

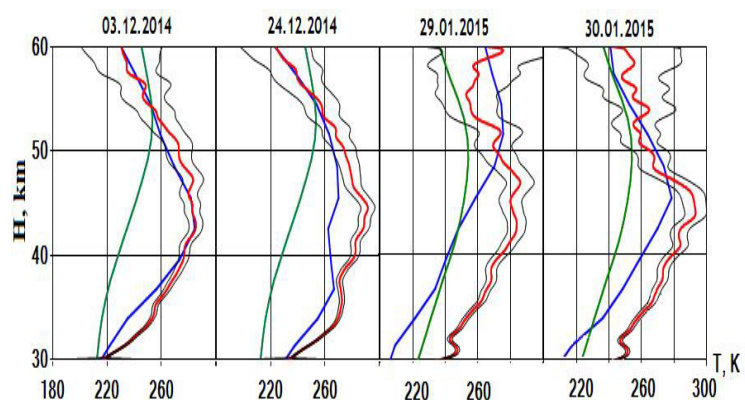

Figure 4 Lidar and satellite observations of the stratospheric warming in December 2014 and January 2015. Red lines show the Rayleigh lidar measurements, black line shows the standard deviation, blue line shows the AURA measurements, and green line shows the monthly mean profile according the CIRA-86 model

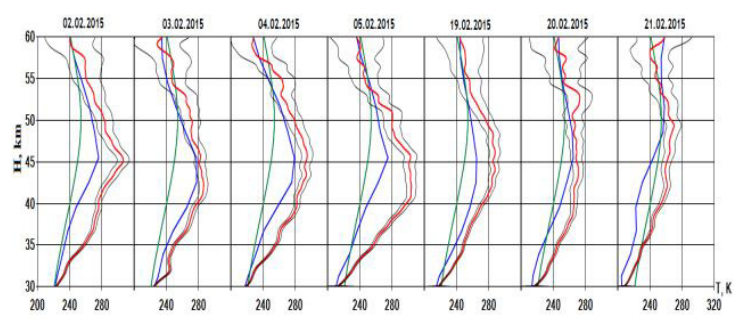

Figure 5 Vertical distribution of temperature in February 2015

The observed SW in 2014-2015 was related to the minor type, when the direction of air mass transfer in the stratosphere did not change from west to east that is confirmed by the data from the web-site [8].

The long-term observations show that the vertical distribution of temperature in Western Siberia in the period March till November is in satisfactory agreement with the CIRA-86 model distribution.

The significant dynamics of the vertical distribution of temperature starts in December (Fig. 6). The positive deviation of temperature from the monthly mean value by approximately $30 \mathrm{~K}$ appears on December 13 at the height of 50 $\mathrm{km}$. Then, on December 18, the area of "warm" air covers the height range from 37 up to $60 \mathrm{~km}$ with the mean value of temperature of about $260 \mathrm{~K}$. The maximum warming is observed on December 29, the temperature in the foregoing height range exceeds $260 \mathrm{~K}$ and reaches $270 \mathrm{~K}$ at the heights of 40 till $50 \mathrm{~km}$. This event is related with the beginning of the next year stratospheric warming.

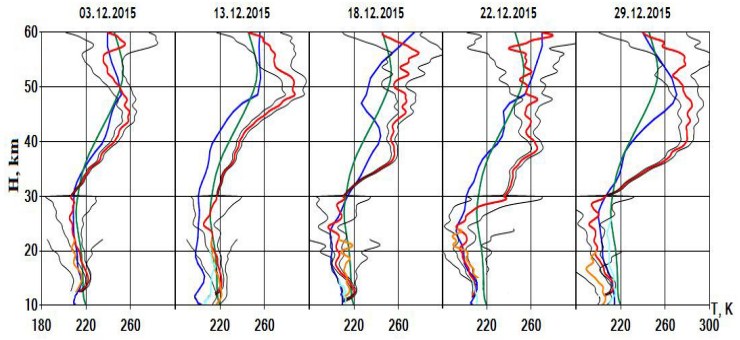

Figure 6 Vertical distribution of temperature in some nights of December 2015
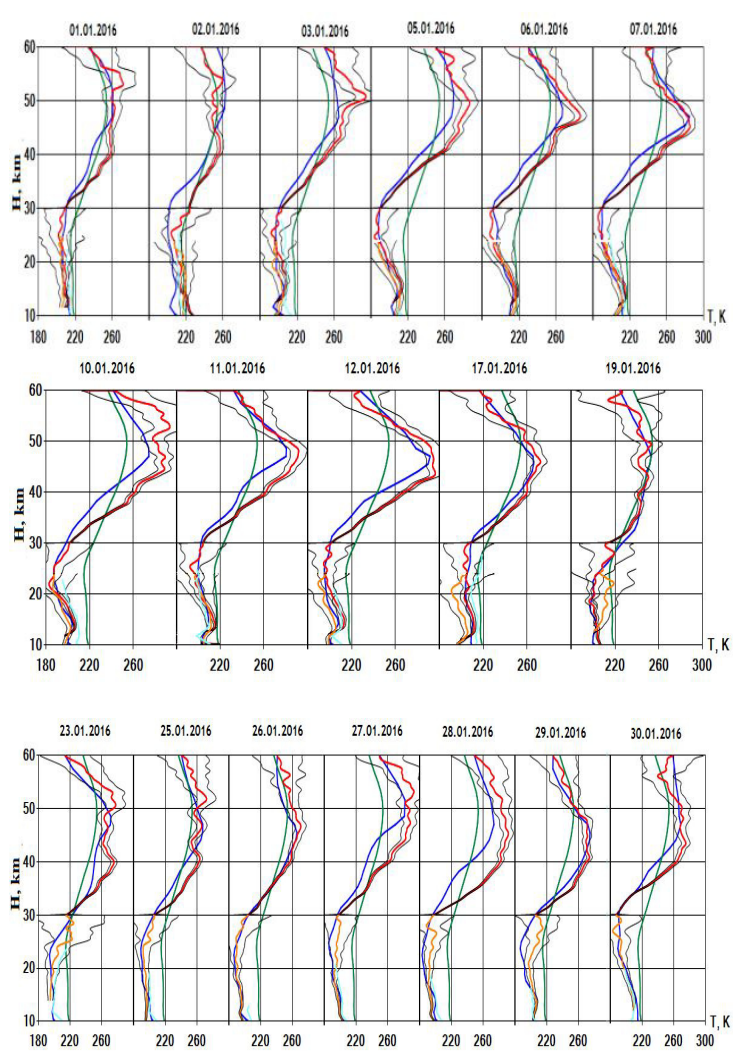

Figure 7 Vertical distribution of temperature in some nights of January 2016. The yellow line shows

Raman lidar measurements, lower blue - radiosonde measurements

In January 2016, for the observation period of January 3 to 17 , the stable vertical temperature distribution was observed in the form of a wave with a positive deviation from the monthly average value in the height range of $40-50 \mathrm{~km}$ and a negative deviation in the lower stratosphere (see Fig. 7). The maximal value of the positive deviation achieved $40 \mathrm{~K}$ (January 12 , height of $45 \mathrm{~km}$ ), and that for the negative deviation was $35 \mathrm{~K}$ (January 5 and 7, height of about $30 \mathrm{~km}$ ).In January 19 to 26 , some stabilization of the vertical temperature distribution (approaching the model distribution) was observed in the upper stratosphere. However, in the entire layer of the lower atmosphere, the temperature profiles obtained 
from lidar, balloon, and satellite data remained shifted toward negative values from the model profile.

The last overshoot of warming was observed on February 1 of 2016 in the height range of 40-60 $\mathrm{km}$.

The observed SW in 2015-2016, as the SW in 2014-2015, were related to the minor type [8].

\section{CONCLUSION}

The lidar studies of the stratosphere over Tomsk in the period of 2015-2016, as well as earlier years, revealed the following:

1. The loading of the stratosphere with background aerosol occurs in the cold period of a year: start in October, maximum in January, and end in April. In the warm period, there is practically no aerosol in the stratosphere.

2. Every year the winter warming takes place in the stratosphere. It begins in December, is most pronounced in January, and is sometimes extended to February. Weak and, more rarely, strong warmings are observed. The amplitude of positive temperature deviations from the monthly average value can achieve $60 \mathrm{~K}$, and the height of the stratopause can go down to $30 \mathrm{~km}$. In the period of March till November, the vertical temperature distribution is in asatisfactory agreement with the CIRA-86 model distribution.

The work was supported by a grant from the RF President (NS-8199.2016.5) in carrying out monitoring measurements, a Russian Science Foundation grant (no. 14-27-00022) to create a receiver for Raman light scattering and Russian Foundation for Basic Research (project no. 1605-00901) in the analysis of the lidar sensing data.

\section{References}

[1] Marichev V.N. Investigation of variability of the background aerosol vertical structure above Tomsk based on lidar observations in 2010-2011, Atmos. Ocean Opt., 2012, 25. No. 11. P. 976-984.

[2] Marichev V.N., Bochkosvkii D.A. Studying the variations in background aerosol loading of the stratosphere in 2014,

Proceedings of SPIE. 2015. V.9680. CID: 9680 6U. [9680-209]

[3] Marichev V.N. Lidar investigations of stratospheric warming events above Tomsk in
2008-2010, Atmos. Ocean Opt. 2011. V. 24. No. 05. pp. 386-391.

[4] Marichev V.N. Investigation into features of manifestation of winter stratospheric warming events over Tomsk from the data of lidar temperature measurements in 2010-2011, Atmos. Ocean Opt. 2011. V. 24. No. 12. P. 1041-1046.

[5] Marichev V.N. The analysis of the air density and temperature behaviour in the stratosphere above Tomsk in periods of perturbed and quiet states performed according to the results of lidar measurements, Atmos. Ocean Opt. 2013. V. 26. No. 09. pp. 783-792.

[6] http://mirador.gsfc.nasa.gov

[7] Rees D., Barnett J.J., Labitske K. COSPAR International Reference Atmosphere: 1986. Part II, Middle Atmosphere Models, Adv. Space Res. 1990. V. 10, N 12. 525 p.

[8] http://users.met.fu-berlin.de/ Aktuell/stratwww/wdiag/eczm.php?alert $=8 \&$ forecast $=$ all \&var= u\&lng= eng\#fig1 